\title{
Seasonal Distribution and Movement of Black Sea Bass (Centropristis striata) in the Northwest Atlantic as Determined from a Mark-Recapture Experiment
}

\author{
Joshua Moser and Gary R. Shepherd \\ National Marine Fisheries Service, Northeast Fisheries Science Center, \\ Woods Hole, MA 02543, USA. \\ Joshua.Moser@noaa.gov and Gary.Shepherd@noaa.gov
}

\begin{abstract}
Moser, J., and G. R. Shepherd. 2009. Seasonal Distribution and Movement of Black Sea Bass (Centropristis striata) in the Northwest Atlantic as Determined from a Mark-Recapture Experiment. J. Northw. Atl. Fish. Sci., 40: 17-28. doi:10.2960/J.v40.m638
\end{abstract}

\begin{abstract}
A mark-recapture experiment was conducted on the northern stock of black sea bass (Centropristis striata) which ranges from southern portions of the Gulf of Maine to Cape Hatteras, North Carolina. Tag recovery data from traditional tags indicate that extensive seasonal movements occur and are not homogeneous throughout the stock. During summer months fish throughout the stock remain stationary in coastal areas with very little mixing among adjacent areas. In autumn, offshore migration toward the edge of the continental shelf begins in the north and progresses southward. During the offshore overwintering period, intermixing of fish from various inshore areas is more frequent. Recaptures following spring inshore migrations demonstrate a high degree of site-fidelity with occasional straying to adjacent areas. Archival data tags suggest that offshore migration coincides with declining water temperature.
\end{abstract}

Keywords: archival tag, black sea bass, fish tagging, migration, temperature

\section{Introduction}

Black sea bass (Centropristis striata) are distributed in the Northwest Atlantic from the Gulf of Maine to the Gulf of Mexico and support valuable recreational and commercial fisheries throughout the range. Within the northern stock between Massachusetts and North Carolina (NAFO Div. 5YZ, 6ABC), these fisheries are seasonal; most landings from the inshore recreational hook and line and commercial trap fisheries occur between May and October, while most of the catches from the commercial offshore trawl fishery occur between November and March (Shepherd and Terceiro, 1994).

The migratory behavior of black sea bass has been inferred from patterns of abundance in state and federal bottom trawl surveys, as well as from the spatial and temporal distributions of the fisheries targeting sea bass (Drohan et al., 2007). North of Cape Hatteras, sea bass generally occur in coastal waters from late spring to autumn, particularly in areas with structured habitat (Able et al., 1995; Drohan et al., 2007). In autumn, fish move to deeper water along the edge of the continental shelf (Musick and Mercer, 1977; Kendall, 1977; Drohan et al., 2007). The seasonal timing of the inshore-offshore migration suggests that movement may be triggered by an environmental cue such as a change in water temperature.

In 2002, a tagging program was initiated by the NOAA Northeast Fisheries Science Center (NEFSC) to examine the seasonal movement patterns of the northern stock of black sea bass. Previous tagging programs (e.g. Massachusetts Division of Marine Fisheries, New Jersey Department of Environmental Protection, American Littoral Society) focused on local aggregations of black sea bass (Kolek, MS 1990; Carlsen, 2000; Vareha and Figley, MS 2004), but none encompassed the entire stock within a single study. The intent of the NEFSC tagging program was to identify movement patterns of black sea bass and examine the extent of mixing north of Cape Hatteras, North Carolina. The time series of recapture data was also intended for use in the estimation of exploitation rates within the stock, however exploitation analyses are beyond the scope of this paper. 


\section{Materials and Methods}

Tagging was conducted annually (2002-2004) within a targeted 21-day window from mid-September to early-October, with additional tag releases in May 2003. Due to weather conditions, several release events were accomplished outside of this window; however, the majority of tagging occurred within the targeted 21-day period. Using a target release number of 2500 tags per season, tagging effort was distributed among coastal states (Massachusetts, Rhode Island, New York, New Jersey, Delaware, Maryland, and Virginia) based on annual state landing quota allocations, and accomplished at regular spatial intervals within each state (Fig. 1).
All fish were captured, tagged, and released aboard chartered commercial and recreational fishing vessels. Standard hook and line gear was used on recreational vessels while commercial vessels used fish traps or hook and line equipment. Fishing was conducted in depths of 2-56 m. Although the size of fish targeted for tagging was larger than the minimum commercial size $(28 \mathrm{~cm})$, black sea bass as small as $19 \mathrm{~cm}$ were tagged. Tag number, date, release location, total length (to the nearest half-centimeter), and relative condition were recorded for each fish tagged.

Tagging was accomplished using Floy internal anchor tags (FM-84), which have provided long term retention

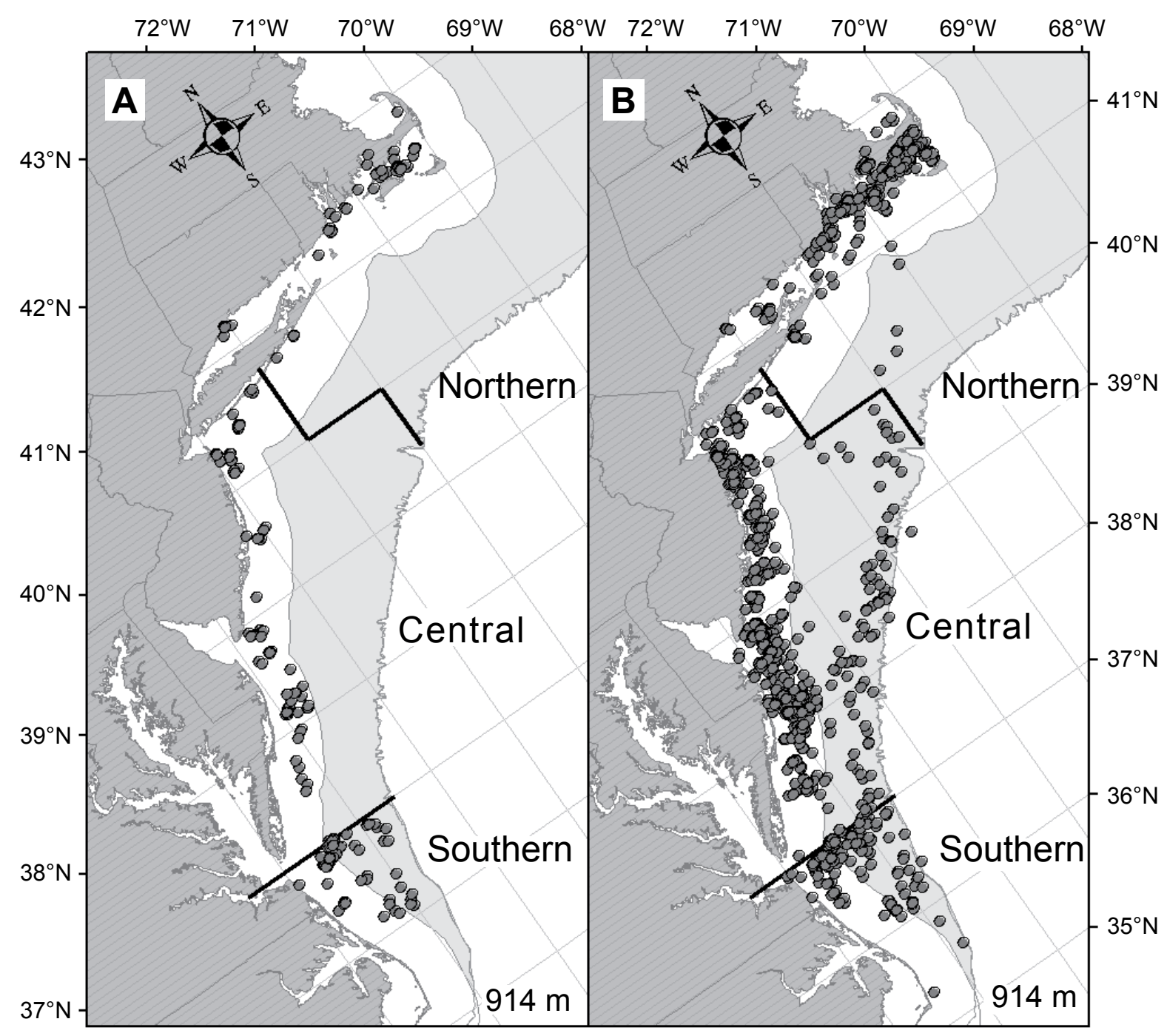

Fig. 1. Tag release (A) and recapture (B) sites of black sea bass between Cape Hatteras, North Carolina and Cape Cod Bay, Massachusetts. Maps show area partitions of tag release and recapture locations. The coastal zone (white) is the area within $60 \mathrm{~km}$ of the shoreline, the offshore zone (light gray) extends from the coastal zone to the $914 \mathrm{~m}$ (500 fm) depth contour. 
in other marine species (Waldman et al., 1991). Previous work by the Massachusetts Division of Marine Fisheries (Kolek, MS 1990) suggested that internal anchor tags were the most appropriate for tagging black sea bass. Each Floy tag had a unique identification number, telephone contact number, and "Reward" printed on both sides of the tag (and in opposite directions) such that the tag number was visible at both the base and end of the tag. Tags were colored and were either orange, which when recaptured and reported was rewarded with a tagging cap, or red which generated a $\$ 100$ reward. After 2004, a lottery reward system was offered as an option to the tagging cap reward.

During tagging, the Floy tag was inserted in the fish at the midpoint of the pectoral fin by making a $5 \mathrm{~mm}$ incision into the abdomen musculature and then gently inserting the tag into the abdominal cavity. Handling time was generally less than one minute, and fish were either released immediately or placed into a holding tank for 2-5 minutes of observation. Sea bass caught at deeper sites often had expanded swim bladders which were deflated when the abdominal incision was made and the tag inserted. Tagged fish which appeared to be in a weakened condition or swimming abnormally were not released. Tag retention rates were determined by holding tagged fish in tanks for observation in three separate studies at the NEFSC Woods Hole and J. J. Howard Labs and at the Rhode Island Department of Marine Fisheries facility in Jamestown.

To examine environmental parameters affecting black sea bass movements, Lotek LTD 1100 external data storage tags (DST) were deployed at locations in Massachusetts, Rhode Island, Maryland, and Virginia. These tags are designed to collect temperature and depth information at regular intervals, and to record time and date of each observation. Information is collected at 15 second intervals with increasing interval lengths the longer the tag is at large. As DSTs must be recaptured and returned to download data, a reward of $\$ 100$ per tag was offered to increase the likelihood of tag returns. The tags were attached to the fish below the dorsal fin by inserting two nickel pins which passed laterally through holes in the tag and the dorsal muscle tissue of the fish. On the opposite side of the fish, the tag was held in place with a plate secured by bending over the ends of the pins. The tags were activated just prior to attachment to the fish.

Recaptured tags were reported by telephone, postal mail, or via an online tag reporting webpage. Information was collected on the date of capture, fish length, gear type and fishery, port, longitude and latitude of recapture if possible (or at least some reference point within several miles), condition of the tag insertion point and of the fish, and fisherman's contact information. Since the precision of black sea bass tag recapture locations varied among fishermen, recaptures were subsequently binned into one degree squares for analysis of movement patterns.

During the three autumn and one spring release periods in 2002 to 2004, a total of 13658 black sea bass were tagged and released with regular tags (12 802) or high reward tags (856) during 22 tagging trips. Fish were tagged and released at 78 sites (Fig. 1) distributed throughout the range of the northern stock of black sea bass.

Large-scale spatial movements were evaluated by partitioning the tag return data into three different areas: north, central, and south (Fig. 1). These areas were based on a qualitative assessment of the tag recapture patterns with boundary delineations following latitudinal and longitudinal degree squares. Area boundaries extend from Long Island to the edge of the continental shelf at the Hudson Canyon, and from the Chesapeake Bay entrance due east to the shelf edge. Coastal waters were defined as the shelf area located within $60 \mathrm{~km}$ of shore. This area was deemed readily accessible to recreational and pot fisheries, as distances greater than $60 \mathrm{~km}$ are less likely to be fished due to fuel costs and travel time. Offshore waters were defined as those between the coastal water boundary and the $914 \mathrm{~m}(500 \mathrm{fm})$ depth contour, which is beyond the depth limit of black sea bass fishing activity. In reference to movements, the $100 \mathrm{~m}$ contour was used to delineate the edge of the continental shelf. The offshore waters are predominantly fished by bottom trawlers although there is a seasonal pot and rod and reel fishery in the southern area.

Black sea bass migratory behavior was categorized using the approach of Robichaud and Rose (2004). Based on the time and location of recapture, five categories of movement behavior were established :

(1) Immediate (I) - those fish caught within the same calendar year as their release, prior to the offshore movement in the autumn;

(2) Home Returns (HR) - fish recovered after returning to a location within $10 \mathrm{~km}$ of their site of release;

(3) Neighbors (NB) - fish recovered after returning to a location between $10-60 \mathrm{~km}$ of their release site;

(4) Re-locators (R) - fish recaptured at a distance greater than $60 \mathrm{~km}$ from their release site but within an adjacent degree square; and 
(5) Strays (S) - fish recovered beyond a one degree square distance from their release location, but within the coastal zone.

Only tagged fish recaptured after 1 January of the calendar year following tagging were considered. Site fidelity was measured as the proportion of HR fish among all recaptures from tagged fish at each release site. The relationship between site fidelity and movement was modeled as the proportion of recaptured fish returning to each tag release site as a function of the average distance $(\mathrm{km})$ between release and recovery location (net displacement).

Timing of the onset of migration was examined using changes in net displacement rate over time. A net displacement rate was calculated as $\mathrm{km}$ per day traveled between release and recovery locations. Changes in the rate of net displacement per week of the year (WOY) were calculated for each of the three areas as the difference between the mean weekly net displacement rate per area and the overall mean. Net displacement rates greater than the overall mean implied an increased rate of movement, whereas rates lower than the overall mean implied more stationarity.

Generalized movement patterns were summarized using a series of seasonal vectors based on the net distance and direction between tag release and recapture locations. The bearing and distance traveled of each recapture were placed into one of 12 directional bins $\left(30^{\circ}\right.$ each) for each release area. Mean bearing and distance traveled were then calculated for each bin and plotted as rose diagrams.

Home range and the degree of overlap for each of the three defined areas were examined using percent volume contours (PVC). The 95\% PVC represents the area of active use, $80 \% \mathrm{PVC}$ is an intermediate reference contour, and the $50 \%$ PVC is the core area of activity (Iverson and
Esler, 2006). The contours were created from rasterized point locations of the recapture tag data in each release area, and then used to create kernel density estimates, which provide the basis for the percent volume contours. Although the majority of highly displaced fish were recaptured in the offshore zone, both coastal and offshore recaptures were considered to account for the movement range of strays. Immediate recaptures (I) were removed from the data set prior to PVC calculation.

\section{Results}

The effects of tagging and subsequent tag loss were addressed in a series of three experiments using fish held in aquaria. A total of 68 fish were held in captivity for up to 354 days resulting in a total of seven tags lost and zero tag-induced mortalities. All tag losses occurred within the first four weeks after tagging. The overall tag retention rate was $90 \%$.

By October 1, 2007, a total of 2450 tagged fish had been recovered (i.e., 17.9\% including those tagged bass with incomplete recapture information). Among recovered tags with complete recapture information (tag number, date and location of recapture, $n=2424$ ), $43.6 \%$ percent of the tagged fish were recovered within the first 60 days at liberty, $80.2 \%$ percent were recovered within the first year, and the longest recorded time between release and recovery was 1417 days (3.9 years). Regular reward tags had an overall reporting rate of $17.4 \%$ and the high reward tags generated returns of $24.6 \%$ implying a reporting rate of $70.7 \%$. Tag recovery information is summarized in Table 1 (data storage tags have been excluded). The mean distance traveled by northern area releases $(58.9 \mathrm{~km})$ was nearly three times that of the central releases $(20.4 \mathrm{~km})$ and four times the distance traveled by southern area releases $(15.7 \mathrm{~km})$. The maximum distance traveled was recorded for a tagged fish released in the northern area and recaptured in the southern area after traveling a net distance

TABLE 1. Tag recapture summary by Northern, Central and Southern release areas. A total of 13658 tag were released of which 2424 were recaptured. The net distance traveled and days at liberty are shown for internal anchor tags (regular and high reward) which were reported with the date and location of recapture; data storage tags are excluded.

\begin{tabular}{|c|c|c|c|c|c|c|}
\hline \multirow[b]{2}{*}{ Area } & \multirow{2}{*}{$\begin{array}{c}\text { Release } \\
\text { count }\end{array}$} & \multirow{2}{*}{$\begin{array}{l}\text { Recapture } \\
\text { count }\end{array}$} & \multicolumn{2}{|c|}{ Distance $(\mathrm{km})$} & \multicolumn{2}{|c|}{ Days at liberty } \\
\hline & & & Mean & $\operatorname{Max}$ & Mean & Max \\
\hline Northern & 3973 & 591 & 58.9 & 715.6 & 223 & 1172 \\
\hline Central & 7292 & 1480 & 20.4 & 391.5 & 203 & 1417 \\
\hline Southern & 2393 & 353 & 15.7 & 167.1 & 227 & 1311 \\
\hline
\end{tabular}


of $715.6 \mathrm{~km}$. Mean days at liberty were similar among all three areas (223, 203 and 227 days for the northern, central and southern areas, respectively).

Based on reported tag recaptures, $60.6 \%$ of the returns were from recreational fishermen, $36.5 \%$ from commercial fishermen, 2.4\% from Federal and State scientists, and $0.5 \%$ unknown. Recaptures by gear type indicate that $64.9 \%$ were caught by hook and line $(60.5 \%$ recreational and $4.4 \%$ commercial), $26.0 \%$ by commercial fish traps, $3.3 \%$ by otter trawls, and $5.8 \%$ by unclassified or unreported gear types. Tag recovery patterns by gear varied by region. In Rhode Island and Massachusetts, tag recaptures were predominately from the commercial fishery whereas in all other states recreational fishermen accounted for the majority of tag returns.

Most of the recaptures occurred during May through August (62.8\%), when fishing effort in the recreational fisheries and in the commercial pot and handline fisheries is high due to the more inshore distribution of black sea bass. The autumn period, between September and November, accounted for $23.8 \%$ of recaptures. The remaining $13.4 \%$ of returns occurred between December and April, and were mostly from the offshore trawl fisheries.

Black sea bass were recovered at depths of 5-265 m. No recoveries were made from the stock area south of Cape Hatteras, North Carolina. Although the seasonal shift in distribution was similar throughout the stock, the exact timing and extent of movement varied from north to south. In the autumn, the seasonal movement offshore began in the north and progressed southward. The reverse was true for the return migration in spring, with overwintering fish off the coast of Virginia and North Carolina being the first to move coastward. The proportion of tag recaptures by area and week of year for Home Returns and Neighbor recaptures combined (within $60 \mathrm{~km}$ of their release site) are shown in Fig. 2. In the northern area, no fish were recaptured within $60 \mathrm{~km}$ of their release site after week 46, while in the central and southern areas fish continued to be recaptured into week 1 of the following

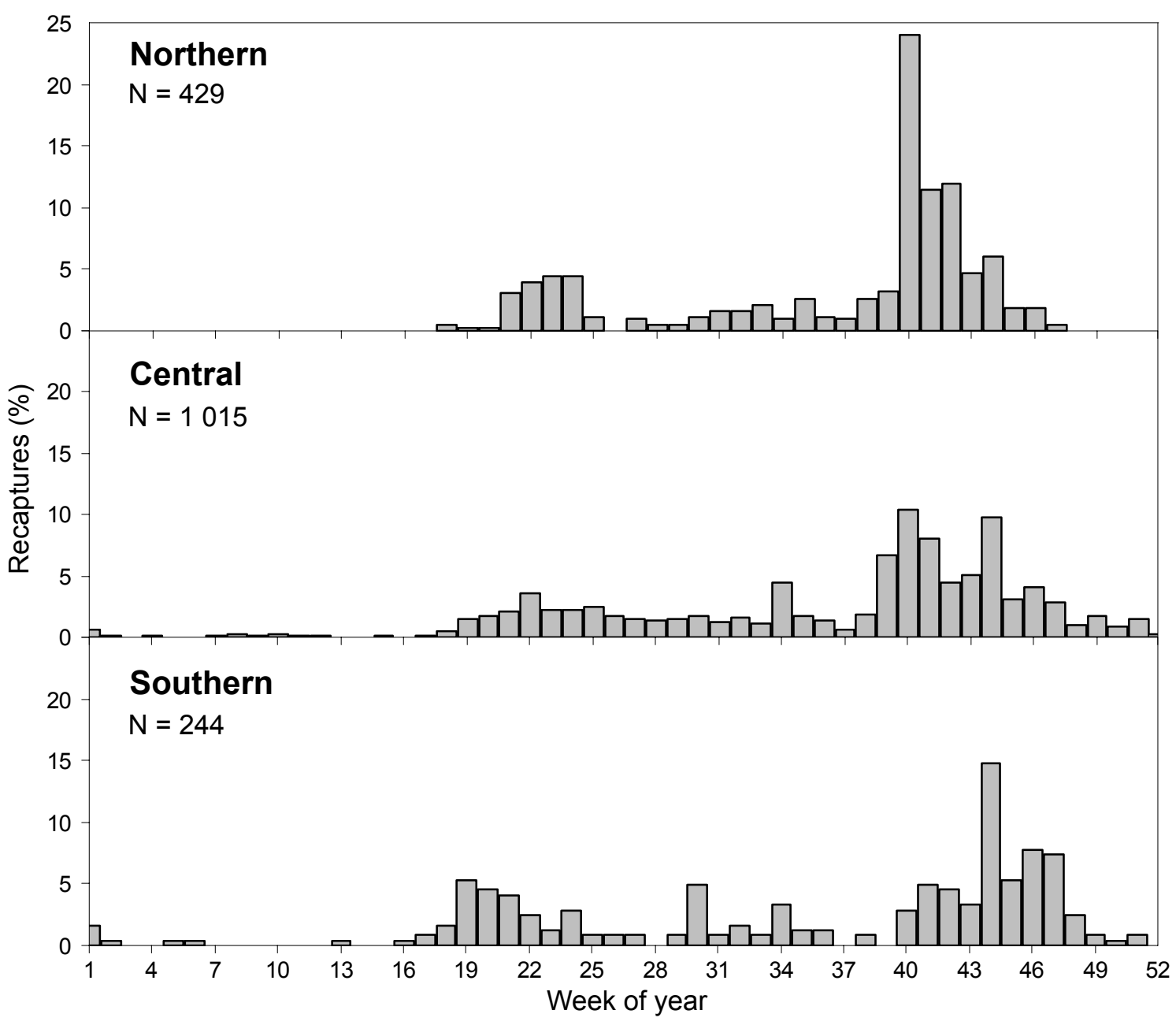

Fig. 2. Home Returns and neighbor recapture combined percentages by area and week of the year. 
year. In spring, recaptures first occurred in the southern area during week 17, in the central area during week 19 and finally in the north during week 21.

Weekly net displacement rates also indicated a seasonal pattern of migratory behavior. The overall mean net displacement rate of $0.3 \mathrm{~km} /$ day served as the basis for weekly comparisons. During the coastal zone residency period (summer), the mean rate of movement for all three areas combined was $0.1 \mathrm{~km} /$ day compared with $0.6 \mathrm{~km} /$ day during offshore zone residence (Fig. 3). Increased movement of fish in the northern area was evident between WOY 49-16 and peaked in week 2 at $3.0 \mathrm{~km} /$ day. Fish released in the central area showed movement between weeks 2 and 16, peaking in WOY 6 at $0.8 \mathrm{~km} /$ day, while movements of fish in the southern area peaked at $0.5 \mathrm{~km} /$ day in WOY 12. In contrast, during the coastal period, black sea bass in all areas remained in the same general locations, as indicated by much lower net displacement rates. During the coastal residence period, the only WOY mean that was higher than the average net displacement rate occurred in the northern area during week 29.

For all recaptured fish, a migratory behavior category was assigned relative to their release area and time at liberty. A total of 900 fish were recaptured in coastal areas after

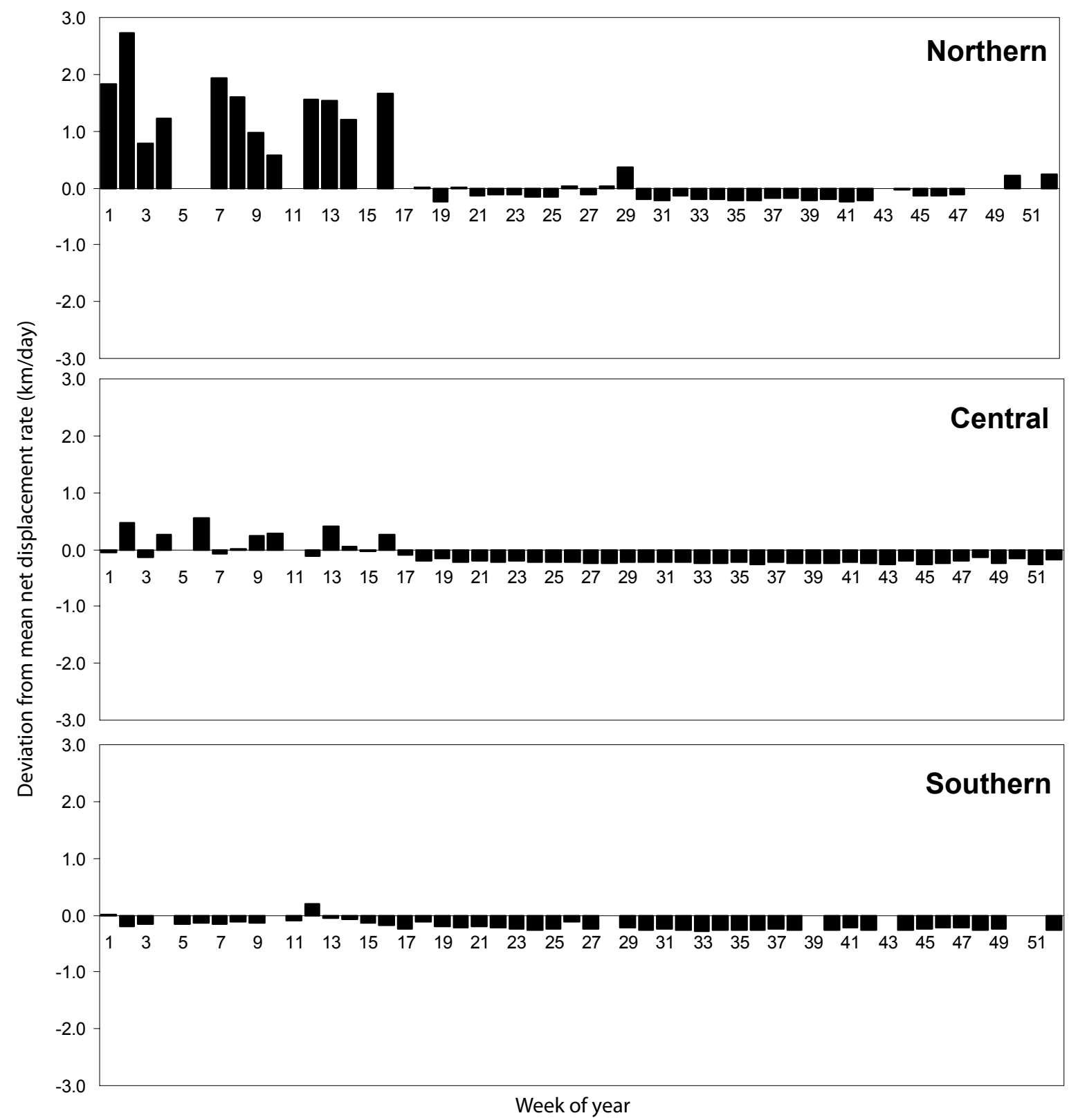

Fig. 3. Average deviation from the mean net displacement rate $(\mathrm{km} /$ day) of black sea bass by area and week of the year. 
TABLE 2. Number of fish released in coastal waters and subsequently recaptured in coastal waters by five movement categories: 1) Immediate (I) - recaptures prior to the offshore movement, 2) Home Returns (HR) - fish recovered after returning to a location within $10 \mathrm{~km}$ of their release site, 3) Neighbors (NB) - fish recaptured $10-60 \mathrm{~km}$ from their release location, 4) Re-locators (R) - recaptured $>60 \mathrm{~km}$ from the site of release but within an adjacent degree square, 5) Strays (S) - fish recovered beyond 1 degree square distant from their release location. Counts are given for each of the three areas Northern $(\mathrm{N})$, Central $(\mathrm{C})$ and Southern (S).

\begin{tabular}{llrrrrr}
\hline \hline Area & I & HR & NB & R & S & Total \\
\hline $\mathrm{N}$ & 305 & 57 & 129 & 48 & 15 & 554 \\
$\mathrm{C}$ & 791 & 289 & 257 & 28 & 3 & 1368 \\
$\mathrm{~S}$ & 184 & 56 & 17 & 1 & 0 & 258 \\
Total & 1280 & 402 & 403 & 77 & 18 & 2180 \\
\hline
\end{tabular}

they had spent at least one full residency period offshore (Table 2). In all areas, more than half of all recaptures (1 280 of 2 180) occurred within the same calendar year of release, prior to movement offshore. After excluding these immediate recaptures (I), $44.7 \%$ of the remaining recaptures (402 fish) were categorized as Home Returns (HR). The northern area experienced the lowest degree of site fidelity (22.9\%), although $74.7 \%$ of the northern recaptures still occurred within $60 \mathrm{~km}$ of their release site $(\mathrm{HR}+\mathrm{NB})$. The central and southern area recaptures were primarily $\mathrm{HR}(50.1 \%$ and $75.7 \%$, respectively) with very low proportions of stray fish. The central area had a straying proportion of $0.5 \%$ while the southern area showed no straying. The degree of site fidelity also varied according to seasonal migration distance (Fig. 4). The relationship between the $\log _{\mathrm{e}}$ of net displacement $(\mathrm{km})$ and percentage of HR (from each release trip) described by the linear regression:

$$
\% \mathrm{HR}=1.159-0.284 \log _{\mathrm{e}}(\text { net displacement })
$$

with $r^{2}=0.71$.

Although there was little mixing during the coastal residence period, mixing among fish from all three areas occurred offshore (Fig. 5). Northern releases were recaptured in all three areas (north $81.8 \%$, central $17.5 \%$ and south $0.7 \%$ ), as were central releases (north $0.3 \%$, central $96.5 \%$ and south $3.2 \%$ ). Southern releases, however, were recaptured almost exclusively in southern areas (94.2\%),

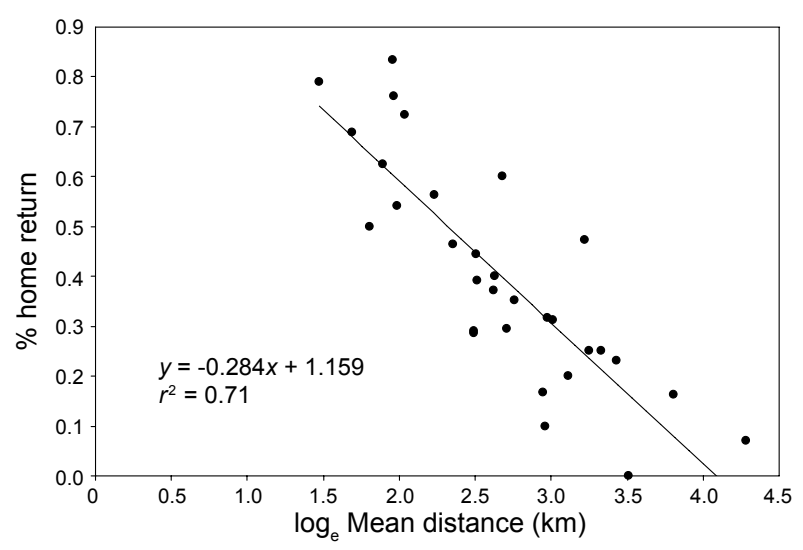

Fig. 4. Percentage of Home Return (fish recovered after returning to a location within $10 \mathrm{~km}$ of their release site) recaptures from each release trip relative to the distance from their site of release.

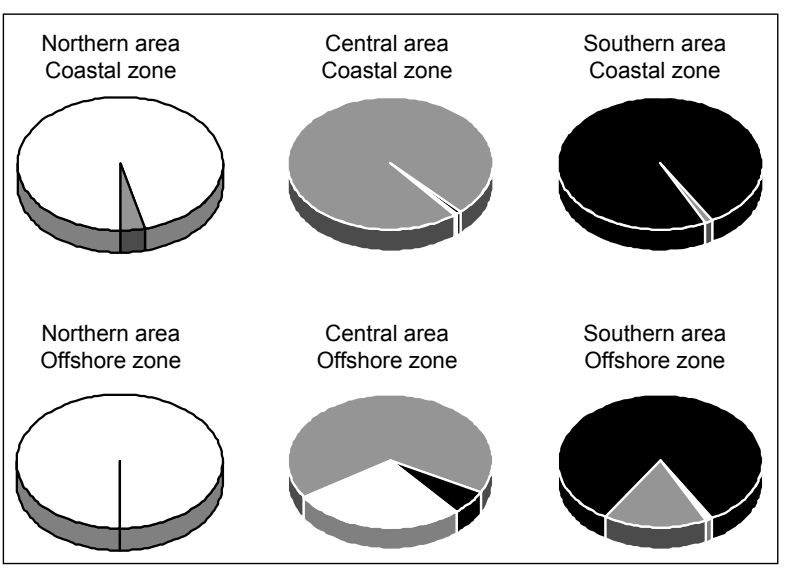

Fig. 5. Relative mixing proportions of fish released from the northern, central and southern areas. Recaptures were subdivided by zone (coastal recaptures on the top row, offshore recaptures on the bottom row). White sections represent recaptures released in the northern area, gray sections represent recaptures released in the central area, and the black sections represent the recapture of southern area released fish.

with a few recaptures in the central area $(5.8 \%)$, and none in the northern area.

The extent of the home ranges of tagged fish in each area differed considerably (Fig. 6). Overlap is evident among all three areas within the 95\% PVC offshore of northern Virginia. For the $80 \%$ PVC, overlap exists between the northern/central areas and the central/southern areas, but the northern and southern contours do not coincide. At the 50\% PVC level, there is no overlap among 


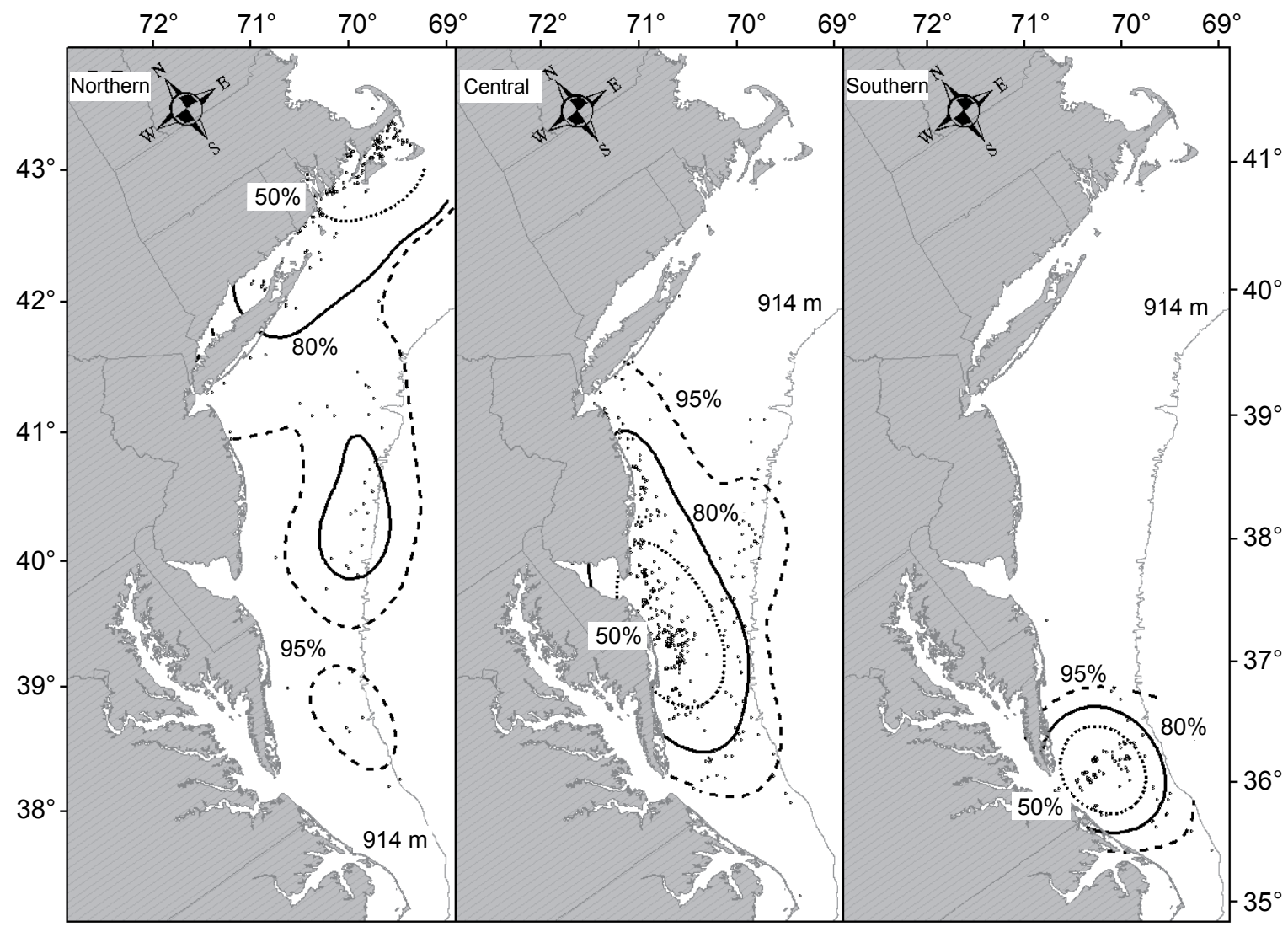

Fig. 6. Percent volume contours of black sea bass tag recaptures released from the Northern, Central and Southern areas. The area within the dashed line contains $95 \%$ of tag recaptures, the solid line contains $80 \%$ of tag recaptures and the dotted line contains $50 \%$ of the recaptured tags from the respective area. Small circles indicate the respective tag recapture locations for tags released in that area.

areas. However, the extent of home range overlap was influenced by the relatively limited temporal overlap among release groups. The region of greatest overlap among all three areas was offshore of Chesapeake Bay.

Rose diagrams depicting the distance and direction of movements of recaptures show that fish tagged in the northern area had the most pronounced directionality, with a strong likelihood for movement toward the southwest (Fig. 7). The northern fish also exhibited the greatest mean travel distance of $60.0 \mathrm{~km}$. Fish tagged in the central area had a mean travel distance of $20.3 \mathrm{~km}$ and average movement vectors toward the south and southeast. In the southern area, movements were more random, distances traveled were much shorter at 15.7 $\mathrm{km}$, and movement probabilities were similar to the east, north, and northwest.

During autumn 2003 and 2004, 162 sea bass were released with data storage tags. However, only eight tags were recovered and seven were returned. Of the seven DSTs, one had corrupt depth records and one had incomplete data (the battery expired prior to recapture), and so both were excluded. Although the five remaining DST tagged fish were at liberty for less than one year (Table 3), movements were evident between the coastal and offshore zones.

The two DST tagged fish released in the northern area ("A" and "B") initiated their offshore movements when bottom water temperatures reached $11.9^{\circ} \mathrm{C}$ during WOY 46 and 48, respectively. Both fish were recaptured prior to returning to coastal waters. As bottom temperature declined to $12^{\circ} \mathrm{C}$, DST-tagged fish "A" began searching for a more preferable temperature range (Fig. 8a). This occurred by moving to deeper, warmer water, in an implied southerly direction. Once the preferred bottom temperature was found, the depth position of fish "A" remained relatively stable until water temperatures again declined. In response, the fish moved to deeper water, closer to the edge of the continental shelf. Eventually, bottom temperatures no longer appeared to be the proximate 


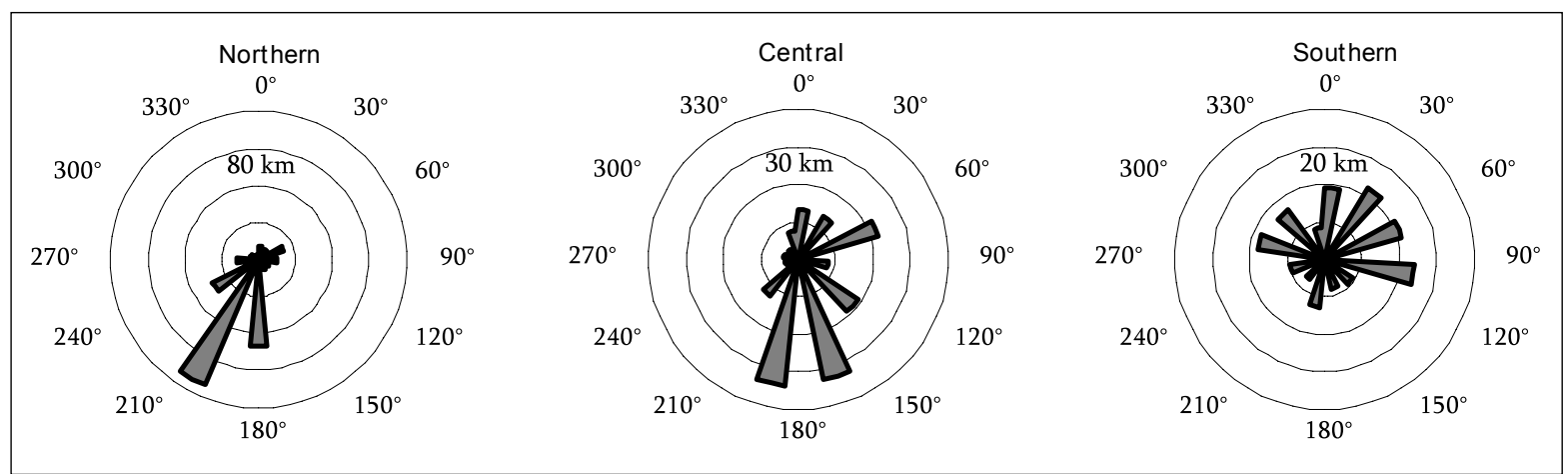

Fig. 7. Rose diagrams of the direction and distance by area from black sea bass tag recaptures.

TABLE 3. Summary of temperature $\left({ }^{\circ} \mathrm{C}\right)$, date and week of year (WOY), days at liberty (DAL) and net distance traveled $(\mathrm{km})$ for five recovered data storage tags (DST) released from the three areas; Northern $(\mathrm{N})$, Central (C), and Southern (S).

\begin{tabular}{|c|c|c|c|c|c|c|c|c|c|c|c|c|}
\hline \multirow[b]{2}{*}{ DST } & \multicolumn{2}{|c|}{ Release } & \multicolumn{3}{|c|}{ Begin Move } & \multicolumn{3}{|c|}{ End Move } & \multicolumn{4}{|c|}{ Recapture } \\
\hline & Area & Date & Date & WOY & ${ }^{\circ} \mathrm{C}$ & Date & WOY & ${ }^{\circ} \mathrm{C}$ & Date & WOY & DAL & $\mathrm{km}$ \\
\hline A & $\mathrm{N}$ & $10 / 11 / 03$ & $14 / 11 / 03$ & 46 & 11.9 & $*$ & $*$ & $*$ & $27 / 02 / 04$ & 9 & 109 & 288.3 \\
\hline B & $\mathrm{N}$ & $10 / 11 / 03$ & $30 / 11 / 03$ & 48 & 11.9 & $*$ & $*$ & $*$ & $30 / 04 / 04$ & 18 & 172 & 341.5 \\
\hline $\mathrm{C}$ & $\mathrm{C}$ & $15 / 11 / 03$ & $11 / 01 / 04$ & 2 & 10.4 & $15 / 05 / 04$ & 20 & 11.3 & $20 / 11 / 04$ & 47 & 371 & 19.6 \\
\hline $\mathrm{D}$ & S & $16 / 12 / 03$ & $21 / 12 / 03$ & 51 & 10.9 & $20 / 04 / 04$ & 16 & 8.3 & $06 / 12 / 04$ & 49 & 356 & 13.5 \\
\hline E & $\mathrm{S}$ & $16 / 12 / 03$ & $23 / 01 / 04$ & 4 & 10.9 & $24 / 03 / 04$ & 12 & 7.5 & $16 / 07 / 04$ & 29 & 213 & 29.8 \\
\hline
\end{tabular}

factor controlling movement as the fish reached a depth of $105 \mathrm{~m}$ and remained there despite a bottom temperature below $11^{\circ} \mathrm{C}$.

The DST-tagged fish released in the central area (tag "C", Fig. 8b) began moving offshore when the bottom water temperature declined to $10.4^{\circ} \mathrm{C}$, which occurred during WOY 2. This fish resettled in coastal waters during WOY 20, when the bottom water temperature was $11.3^{\circ} \mathrm{C}$. The fish was recaptured 27 weeks later (WOY 47) after 371 days at liberty and having traveled a net distance of $19.6 \mathrm{~km}$.

The two DST-tagged fish released in the southern area ("D" and "E") began moving when bottom water temperatures fell to $10.9^{\circ} \mathrm{C}$, although the timing of these movements was separated by five weeks (WOY 51 and 4 respectively). The depth distribution of these fish stabilized during WOY 16 and 12, respectively, at water temperatures of 8.3 and $7.5^{\circ} \mathrm{C}$ (Fig. 8c). Fish "D" was recaptured only a few weeks prior to the following year's offshore movement (WOY 49) after 356 days at liberty and a net travel distance of $13.5 \mathrm{~km}$. Fish "E" was recovered in summer (WOY 29) after 213 days at liberty, $29.8 \mathrm{~km}$ away from its release site.
Variations in the extent of the offshore migrations by each of the five DST-tagged fish produced differences in maximum recorded depths (Table 4). Maximum depths were reached between mid-January and late March, with maximum depths attained in February for three of the fish. The greatest depths were recorded for the two DSTtagged fish ("A" and "B") released in the northern area (174 $\mathrm{m}$ and $404 \mathrm{~m}$ ), followed by fish " $\mathrm{C}$ " released in the central area $(159 \mathrm{~m})$. The two DST-tagged fish released in the southern area ("D" and "E") remained in relatively shallow waters ( $84 \mathrm{~m}$ and $51 \mathrm{~m}$, respectively) throughout the winter months.

\section{Discussion}

The seasonal migratory behavior of black sea bass is not homogeneous throughout the northern stock. In southern New England, at the northern end of the stock's distribution, sea bass move offshore in the autumn as water temperatures decline. During late autumn and winter, these fish depart coastal waters and migrate onto the continental shelf, where they move southward traveling along the shelf edge as far south as Virginia. In contrast, fish tagged at the southern end of the range in Virginia move offshore several months later. Although the movements of both 

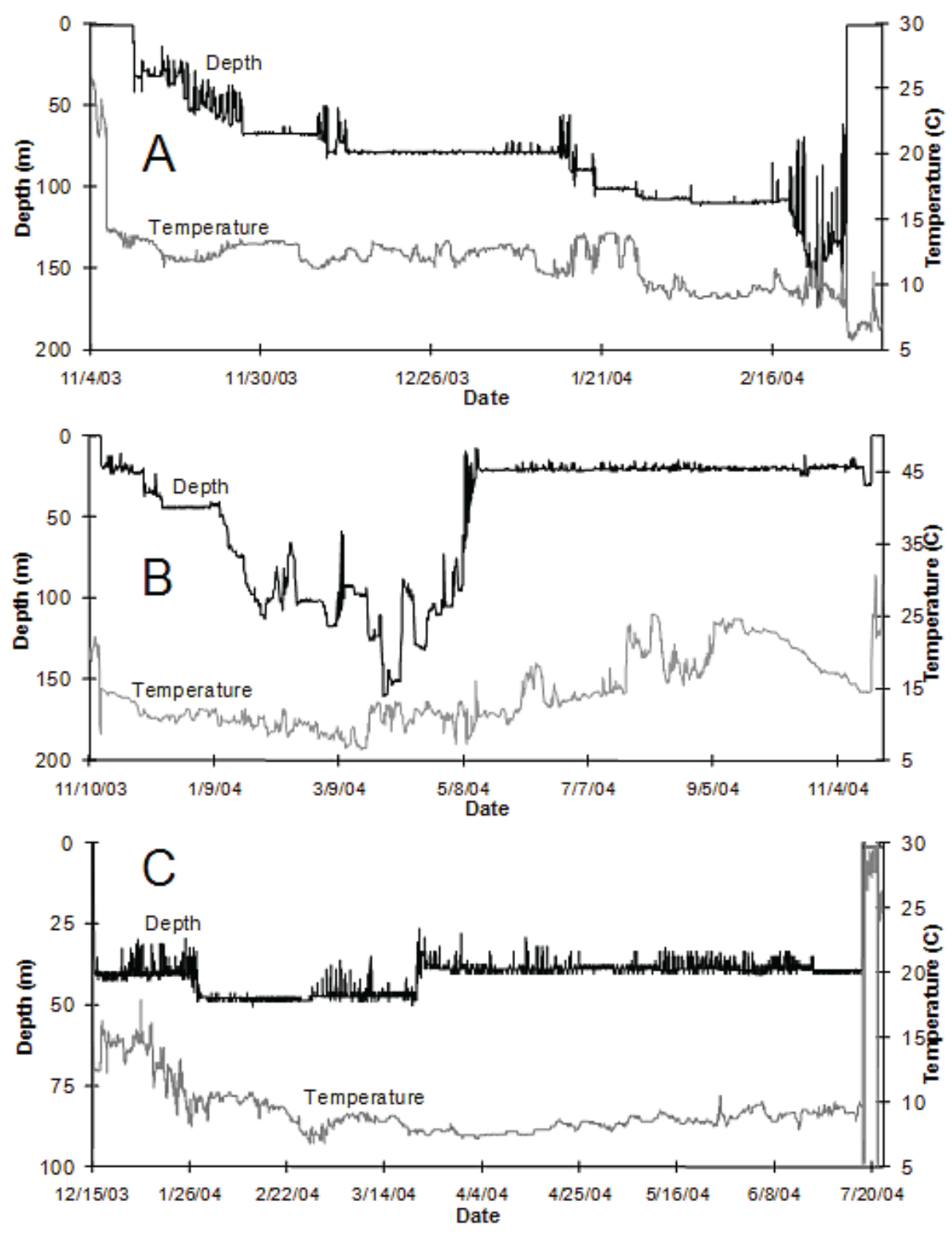

Fig. 8. Temperature and depth data collected from data storage tags; (A) northern release, tag "A", (B) central release, tag "C", and (C) southern release, tag "E".

TABLE 4. Summary of depth records for the five recovered data storage tags (DST) released from the three areas Northern $(\mathrm{N})$, Central $(\mathrm{C})$, and Southern $(\mathrm{S})$.

\begin{tabular}{|c|c|c|c|c|c|c|c|}
\hline \multirow[b]{2}{*}{ DST } & \multirow[b]{2}{*}{ Area } & \multicolumn{2}{|c|}{ Begin Move } & \multicolumn{2}{|c|}{ Max Depth } & \multicolumn{2}{|c|}{ End Move } \\
\hline & & Date & Depth (m) & Date & Depth (m) & Date & Depth (m) \\
\hline A & $\mathrm{N}$ & $14 / 11 / 03$ & 32 & $23 / 02 / 04$ & 174 & * & $*$ \\
\hline B & $\mathrm{N}$ & $30 / 11 / 03$ & 45 & $13 / 01 / 04$ & 404 & $*$ & $*$ \\
\hline $\mathrm{C}$ & $\mathrm{C}$ & $11 / 01 / 04$ & 42 & $31 / 03 / 04$ & 159 & $15 / 05 / 04$ & 20 \\
\hline $\mathrm{D}$ & $\mathrm{S}$ & $21 / 12 / 03$ & 28 & $04 / 02 / 04$ & 84 & $20 / 04 / 04$ & 26 \\
\hline $\mathrm{E}$ & S & $23 / 01 / 04$ & 41 & $15 / 02 / 04$ & 51 & $24 / 03 / 04$ & 38 \\
\hline
\end{tabular}


northern and southern fish coincide with declining water temperatures, the migratory pathway of the southern fish is much different due to their closer proximity to the shelf edge. To reach the overwintering area, southern fish need only travel a limited distance due east. The recaptured fish displayed the same general seasonal distribution patterns as described for the northern stock (Musick and Mercer, 1977; Kendall, 1977; Drohan et al., 2007); that is, recaptured fish were predominately inshore and along the coast during spring to autumn, and offshore waters during autumn through early spring.

Results from the data storage tags suggest that changes in bottom temperature serve as a proximate cue which initiates the autumn offshore migration. Initiation of movement coincided with bottom water temperatures between $10-12^{\circ} \mathrm{C}$, similar to the findings suggested by Kendall (1977) and further supported by anecdotal information provided by local commercial pot fisherman. Fish movements cued by water temperature have been previously documented for a variety of species and species assemblages in the northwest Atlantic (Nesbit and Neville, 1935; Colvocoresses and Musick, 1984). Nesbit and Neville (1935) described the aggregate movement of black sea bass, fluke (Paralichthys dentatus), and scup (Stenotomus chrysops) based on water temperature changes. These three species have slightly different temperature tolerances, but their movements are driven by similar temperature fluctuations. The temperature trigger may also be associated with feeding habits since Atwood $e t$ al. (2001) reported that juvenile black sea bass in aquaria ceased feeding at $10-11^{\circ} \mathrm{C}$. Although the DST-tagged black sea bass in our study showed a preference for water temperatures above $10^{\circ} \mathrm{C}$, this did not persist throughout the winter indicating that some other environmental variable (such as salinity) is also influential in affecting bathymetric and spatial movements.

Migratory movements of black sea bass in the southern area were much more limited than in the more northerly areas, and the southern fish spent the least amount of time offshore. In the southern area, inshore bottom temperatures remain suitable longer in the autumn and warm earlier in the spring and consequently the travel distance and time required for sea bass to find suitable temperatures in winter are relatively less than for fish in the northern area. The DST data indicate that tagged fish released in the central and southern areas used the same patterns of searching as the northern fish, but displayed more sedentary behavior with shorter spans of time spent searching for appropriate temperatures. The net change in depth was approximately $50 \mathrm{~m}$ for the southern fish, $140 \mathrm{~m}$ for the central area fish, and $150 \mathrm{~m}$ for the northern fish. Consequently, north to south variations in the onset of sub-optimal bottom water temperatures dictate the clinal differences among the sea bass in the three areas in the initiation of the autumn offshore migration.

Area differences in migratory behavior are further supported by the analysis of movement distance and direction. Most northern sea bass traveled southwest to the shelf edge near the Hudson Canyon, but some fish were recovered as far south as North Carolina. Sea bass leaving northern locations reach the deeper shelf-edge waters in four to nine weeks based on the DST data. Black sea bass in the central area (e.g., New Jersey, Maryland and Delaware) move offshore southeast to the shelf edge within three weeks. Southern fish move offshore primarily east or northeast, with movement occurring within one to three weeks; however, the DST data do not show these fish reaching the outer edge of the continental shelf. Rather, the southern fish migrate offshore to maximum depths between 47-54 m, according to the DST records. Again a north to south clinal progression was evident, with northern releases requiring far more time than southern fish to cover the distance between their coastal and offshore residences. This is a reflection of both the distance traveled to reach their destination and the timing of the onset of cold water conditions in the coastal habitats.

The return migration of black sea bass to coastal water appears to be much faster and more directed than the offshore migration. Sea bass tagged in Massachusetts have been recovered off the coast of North Carolina in March, yet the majority of tag recoveries in May for the same release cohort occurred in Massachusetts. Black sea bass generally returned to the area of their previous summer residence period, despite mixing among local groups during the winter in offshore areas. However, the degree of tagging site fidelity was also a function of the distance traveled during the autumn migration. That is, the further sea bass migrated offshore, the less likely they would be to return directly to the original inshore location. Although the general return directions were correct, black sea bass were not involved in "homing" behavior - but rather what Dingle and Drake (2007) refer to as "to-and-fro" migrations. The limited degree of return straying supports the conclusion of Shepherd (1991) that local groups of black sea bass exist, but also contributes to clinal gradients in meristic and morphometric characteristics. This level of straying may also be adequate to produce genetic uniformity among sea bass in the northern stock.

The search for preferred temperatures, as indicated by the DST data, implies that habitat preference may be a driving force in black sea bass migrations. The benefits of seeking a preferred habitat must be high enough to offset the physiological costs associated with a long distance migration and potential influences on life history parameters such as growth, maturity and reproductive success. The 
areal specific behavioral differences exhibited by black sea bass may have important implications on the population dynamics of the northern black sea bass stock.

\section{Acknowledgements}

We gratefully acknowledge the numerous participant vessels and volunteers who aided in tag releases and/or in the reporting of recaptured tags, the success of this study would not have been possible without their help and knowledge. State and federal fishery agencies between Massachusetts and Virginia provided expert help in the tagging program. This study was funded through a grant from the MARFIN program and the Northeast Fisheries Science Center. Special acknowledgement needs to be given to Roy Pemberton who expended significant time and effort offshore of Virginia, and the Rhode Island Division of Marine Fisheries who willingly hosted the

\section{References}

ABLE, K. W., FAHAY, M. P., and G. R. SHEPHERD. 1995. Early life history of black sea bass, Centropristis striata, in the mid-Atlantic Bight and a New Jersey estuary. Fish. Bull., 93: 429-445.

ATWOOD, H. L., YOUNG, S. P., TOMASSO JR., J. R., and T. I. J. SMITH. 2001. Salinity and temperature tolerances of black sea bass juveniles. $N$. Am. J. Aquac., 63: 285-288. doi:10.1577/15488454(2001)063<0285:SATTOB $>2.0 . \mathrm{CO} ; 2$

CAR LSEN, P. 2000. Profile of the American Littoral Society's fish tagging program. Fisheries, 25: 16-17. COLVOLCORESSES, J. A., and J. A. MUSICK. 1984. Species associations and community composition of Middle Atlantic Bight continental shelf demersal fishes. Fish. Bull., 82: 295-313.

DINGLE, H., and V. A. DRAKE. 2007. What is migration? Bioscience, 57: 113-121. doi:10.1641/B570206

DROHAN, A. F., J. P. MANDERSON, and D. PACKER. 2007. Essential Fish Habitat Source Document: Black sea bass,
Centropristis striata, life history and habitat characteristics. $2^{\text {nd }}$ Edition. NOAA Tech. Memo. NMFS-NE-200, 78 p.

IVERSON, S. A., and D. ESLER. 2006. Site fidelity and the demographic implications of winter movements by a migratory bird, the harlequin duck Histrionicus histrionicus. J. Avian Biol., 37: 219-228. doi:10.1111/j.2006.09088857.03616.x

KENDALL, A. W. 1977. Biological and fisheries data on black sea bass, Centropristis striata. NEFC Sandy Hook Lab. Tech. Ser. Rep., No. 7, 29 p.

KOLEK, D. MS 1990. Homing of black sea bass, Centropristis striata, in Nantucket Sound with comments on seasonal distribution, growth rates, and fisheries of the species. Massachusetts Div. Mar. Fish. Pocassett, MA, 12 p.

MUSICK, J. A., and L. P. MERCER. 1977. Seasonal distribution of black sea bass, Centropristis striata, in the Mid-Atlantic Bight with comments on the ecology of fisheries of the species. Trans. Am. Fish. Soc, 106: 12-25. doi:10.1577/15488659(1977) $106<12$ :SDOBSB $>2.0 . \mathrm{CO} ; 2$

NESBIT, R. A., and W. C. NEVILLE. 1935. Conditions affecting the southern winter trawl fishery. U.S. Dep. Commer. Bur. Fish., Fish. Circ., No. 18, 12 p.

ROBICHAUD, D., and G. A. ROSE. 2004. Migratory behaviour and range in Atlantic cod: inference from a century of tagging. Fish Fish., 5: 185-214. doi:10.1111/j.14672679.2004.00141.x

SHEPHERD, G. R. 1991. Meristic and morphometric variation in black sea bass north of Cape Hatteras, North Carolina. N. Am. J. Fish. Manage., 11: 139-148. doi:10.1577/15488675(1991)011<0139:MAMVIB>2.3.CO;2

SHEPHERD, G. R., and M. TERCEIRO. 1994. The summer flounder, scup, and black sea bass fishery of the Middle Atlantic Bight and southern New England waters. NOAA Tech. Rep. NMFS, No. 122, 18 p. http://spo.nwr.noaa.gov/ tr122.pdf

VAREHA, D., and B. FIGLEY. MS 2004. Tagging study of black sea bass in New Jersey ocean waters - Preliminary results. NJ Dep. Env. Prot., 10 p.

WALDMAN, J. R., DUNNING, D. J., and M. T. MATTSON. 1991. Management Briefs: Long-term retention of anchor tags and internal anchor tags by striped bass. $N$. Am. J. Fish. Manage., 11: 232-234. doi:10.1577/15488675(1991)011<0232:MBLTRO >2.3.CO;2 
Errata: Fig. A corrected and replaced on page 26.
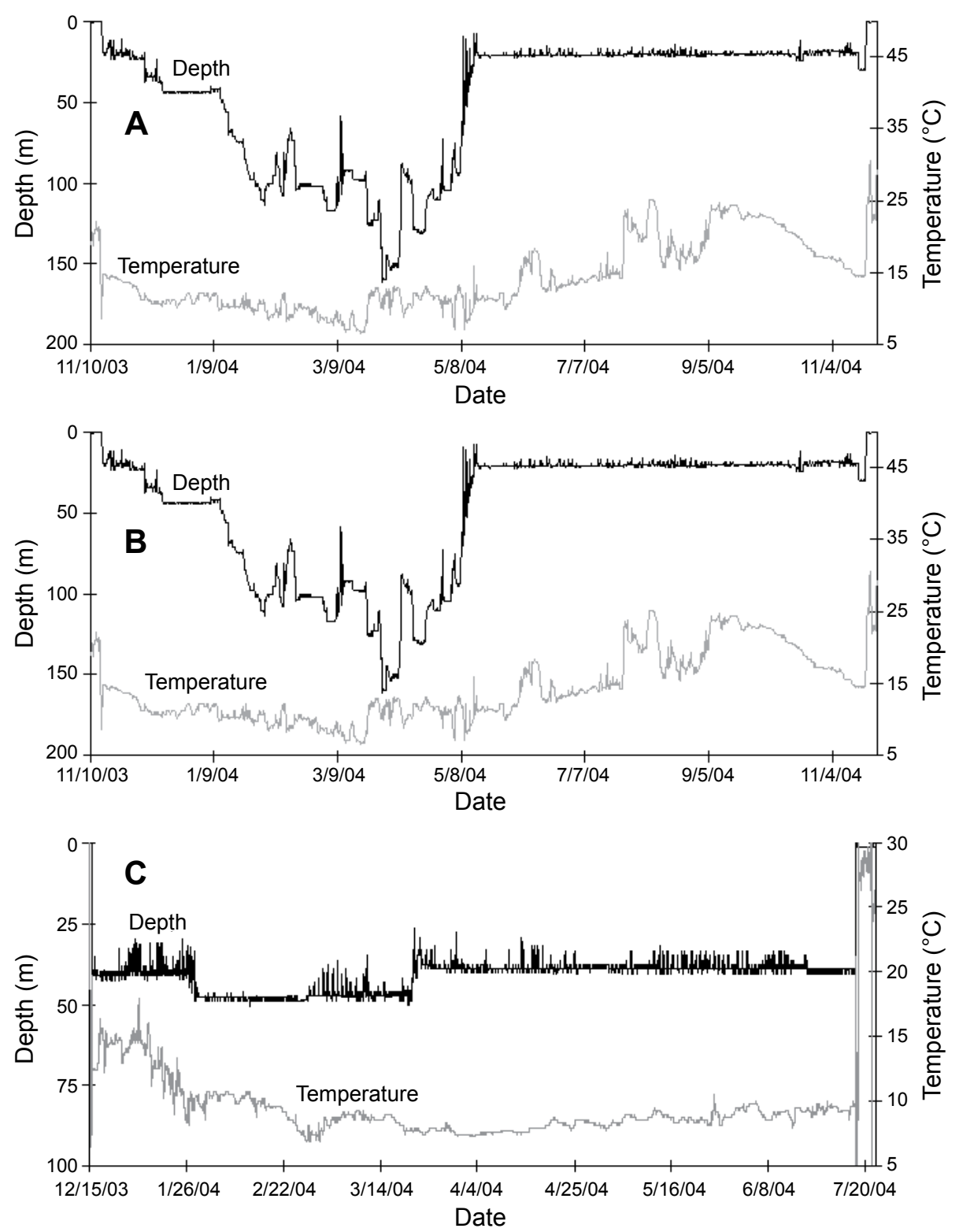

Fig. 8. Temperature and depth data collected from data storage tags; (A) northern release, tag "A", (B) central release, tag "C", and $(\mathbf{C})$ southern release, tag "E".

TABLE 4. Summary of depth records for the five recovered data storage tags (DST) released from the three areas Northern $(\mathrm{N})$, Central (C), and Southern (S).

\begin{tabular}{|c|c|c|c|c|c|c|c|}
\hline \multirow[b]{2}{*}{ DST } & \multirow[b]{2}{*}{ Area } & \multicolumn{2}{|c|}{ Begin Move } & \multicolumn{2}{|c|}{ Max Depth } & \multicolumn{2}{|c|}{ End Move } \\
\hline & & Date & Depth (m) & Date & Depth (m) & Date & Depth (m) \\
\hline A & $\mathrm{N}$ & $14 / 11 / 03$ & 32 & $23 / 02 / 04$ & 174 & $*$ & $*$ \\
\hline B & $\mathrm{N}$ & $30 / 11 / 03$ & 45 & $13 / 01 / 04$ & 404 & $*$ & $*$ \\
\hline $\mathrm{C}$ & $\mathrm{C}$ & $11 / 01 / 04$ & 42 & $31 / 03 / 04$ & 159 & $15 / 05 / 04$ & 20 \\
\hline $\mathrm{D}$ & $\mathrm{S}$ & $21 / 12 / 03$ & 28 & $04 / 02 / 04$ & 84 & $20 / 04 / 04$ & 26 \\
\hline $\mathrm{E}$ & S & $23 / 01 / 04$ & 41 & $15 / 02 / 04$ & 51 & $24 / 03 / 04$ & 38 \\
\hline
\end{tabular}

